\title{
Study on Cultivation Quality Evaluation Mode of Talents Specialized in Art Design
}

\author{
Jiefang $\mathrm{Yu}$ \\ School of Art and Design \\ Huanghe Science and Technology College \\ Zhengzhou, China 450046 \\ E-mail:jwb315@foxmail.com
}

\begin{abstract}
Quite a lot students cultivated by higher education schools cannot adapt to the social development needs as the society is continuously developing and the whole economic structure is under adjustment step by step. Meanwhile, the higher education in our country has walked into the phase of popularity from the elite talents cultivation period, and the popularized higher education is in pursuit of a quality-oriented education. Those objective factors have formed a foundation for a number of higher education reforms including the education evaluation. As for the colleges, they need to take initiatives to carry out education reform to improve education quality and to make the graduates cultivated by them acknowledged fully and praised highly by the society.
\end{abstract}

Keywords-art design specialty; talents cultivation; evaluation mode; study

\section{INTRODUCTION}

It is a comprehensive test on students' degree of learning of basic knowledge, basic theory and basic skills through the evaluation of talent cultivation quality via the "Three-basic" test. In short, it is a test on student's basic quality and occupational skills. The "Three-basic" test on students with art design specialty may have contributed to the inspection of cultivation quality of the design talents in colleges.

\section{PURPOSE AND SIGNIFICANCE OF THE TALENT Cultivation Quality Evaluation}

As one of the means of monitoring and evaluation of the teaching quality, the primary purpose of this test is to enhance education quality and promote students' development. As one form of evaluation, the "Three-basic" test is responsible for the accountability of courses, teaching and the learning effect. What is more important is its function of serving, namely to provide information, feedback or backflow for course construction, teaching reform and indepth learning of the students. The evaluation results and data information are used for improving the education, and it be used to aim at the development and construction, as well as the teachers' teaching and students' learning.

\section{EVALUATION MODE REFORM}

We have conducted tests of four semester on the courses opened up in previous academic year of the undergraduates majored in art design. In consideration of various factors in education, such as difficult measurement of students' learning attitude, emotion, character and ambitions, are very important to students' personal growth and development, therefore, we have adopted such measurements as hand drawing and practical operation for quite a number of majors on the basis of the standardized written examination, to make the instrumental value and humanistic value complement each other as far as possible.

\section{EVALUATION CONTENTS REFORM}

In order to break through the dilemma of singleness and narrowness of evaluation information, and to make the test results more objective, the test contents shall cover the following three aspects: Firstly, the course, namely the teaching materials on narrow sense, is generally regarded as the main contents and medium for teaching. Under such circumstance, the standardized test covering the course contents is taken as an important tool to evaluate teachers' teaching effect and an effective way to test students' learning. Secondly, the national standardization occupational qualification test, which focuses on the learning foundation with a wide coverage and strong comprehensiveness, is the means of national occupational qualification tests, and this is another significant part for the "Three-basic" test. Thirdly, it is a test focusing on students' occupational attitude, occupational ability and occupational quality with the design companies to participate in setting the questions. The three afore mentioned tests not only pay attention to students' learning of the standardized basic theory, basic knowledge and basic skills, but also give consideration to students' ability, attitude, emotion and planning etc.

\section{Evaluation Practice Situation AND ANALYSis}

In recent two years, there are 24 course for the "Threebasis" test, namely 6 compulsive course of general education, 5 core course of the subject, 11 core specialized courses and 2 national occupational qualification tests. And 779 students in total of six majors (directions) have participated in the test. 
The resources for the questions set in the test are diversity, with the questions set by design companies, the questions from national standardization occupational qualification tests, and questions set by experts from other colleges as the main channel, and questions selected from our college test paper bank or set by our college's experienced experts for specific courses as supplement.

We have conducted conclusive analysis against test results, and the data from general education courses test first of all indicates that students have been influenced by the exam-oriented education. Students just pay attention to whether or not they can pass the exam while learning such courses, and not to study the basic theory in-depth. And the next is that most of the students, who have poor basic knowledge and lack of the motivation and passion for learning basic theory, hold the opinion that they just need to pay attention to the professional learning. The test results form professional core courses and subject core courses further indicates that the performance of professional teaching is positive, and this the good teaching effects brought by our focus on the professional courses reform. The statistical data also reflects the huge difference between students' mastering and application of the comprehensive professional knowledge and theory of subject core course to some extent, and the attitude to professional basic courses learning and professional theory courses learning can even not be put on the same level. There is quite big difference in average score and pass rate among the grades which reflects the difference of teaching effects among different courses in some aspects.

The results from national occupational qualification test show a low average score and pass rate of the students. The problems are as follows by analysis: the questions in Photographer Qualification Test belonging to the content of Photography Technician Level Test, which are beyond students' actual level and knowledge scope, are quite difficult for the undergraduates in our college. And the Graphic Designer Qualifications Examination is just to test the photoshop7.0 software theory, which is mainly aiming to test students' mastering of software pure theory. While the cultivation program for software course opened up for students specialized in art design just requires the students to operate software proficiently, without any specific requirements for mastering of the pure theory.

There is a common problem existing in the students specialized in art design by the test results: they have difficulty in learning culture courses, especially in learning common education courses in foreign language during the academic years due to their low cultural quality at the time of admission, and this has limited their studying on excellent cultural knowledge to a large extent. The motivation of students to learn such basic courses as Fine Art Theory and Art History is quite low and their lack of comprehensive knowledge is obvious to see. During school hours, most of them just pay attention to the learning of professional skills, thus the "prefer skill to culture" is formed. And they have no rich cultural basic knowledge background with no personal enriching and cultivation it consciously, which has limited their understanding of the art works seriously, resulting in an insufficiency of their mastering of different designers (painters)' work styles in different times, their recognition of the works' inner structure, and their understanding of the emotional contained in the works. As a result, they cannot make a perfect and accurate understanding and performance of the works.

\section{EVALUATION ON IMPROVEMENT MEASURES AND IMPLEMENTATION EFFECTS}

The outstanding feature of the professional teaching within art design major is to consistently attach importance to combining teaching with practice, and combining teaching with society and market in the process of teaching reform, and through continuous improvement of students' ability of technical operation, and the ability to combine society with design market, to reinforce the segments of practical training, market researching and society investigation in the whole process of teaching. In combination with "Three-basic" test results and the existing problems, our college has conducted in-depth discussions with the teaching and research office, and has studied the characteristics of various professional teachings carefully to further strengthen the teaching reform. A series of measures have been taken to guarantee enhancement of teaching quality. The following major aspects have been carried out and improved in the process of teaching:

\section{A. Further Strengthen the Training of Students' Practical Ability Upon the Freshmen Entered Our College to Consolidate Their Professional Basis, and Improve Cultivation Intensity of Modeling Ability Against Professional Requirements}

For example, guide the students to strength their learning of such courses as Basic Structure Sketching, Design Color, Expression Methods of Professional Basic Design and Computer Aided Design. And from the academic year of 2009 , each professional course of the art design major shall require sketches, with $30 \%$ of which recorded in the total results, and the sketch contents may adjust in accordance with the professional courses.

\section{B. Take the "Freshman Seminar" and "Senior Class}

Seminar" as an Opportunity, to Continuously Explore

Teaching Methods Reform, and to Enrich and Broaden

Students' Horizons, Thus to Arouse Their Interest in

Professional Courses

For instance, in Seminar teaching, let students play a leading role, and by adopting the learning mode of group discussion and mutual competition, to motivate their learning passion and creativity. Meanwhile, plenty of extracurricular materials have been provided to the students to expand their scope of knowledge.

\section{Pay Attention to Class Teaching, Lay Emphasis on Students' Active Thinking Development and Innovation Ability Cultivation While Teaching Theory}

In class teaching, teachers attach importance to the active guidance and exploration of the thoughts in their creativity 
and innovation process while teaching their knowledge, which is the teaching segment that our major takes seriously in class teaching. And we have accumulated and summarized some experience through our positive endeavor and exploration in this aspect. For example, the course group of Character Design and Format Design has stimulated students' creativity and explored their potential in short time through real time test and training in class teaching by setting questions and taking test on the spot, and analysis on the spot after the test, enabling the students to experience design process and enjoy the pleasure of achievements.

Through teaching practice, we hold the opinion that the teaching mode of putting students in leading place with group discussion and appraisement, and then using the teaching method of "Plus \& Minus" to screen excellent creative manuscript in the state of creative design, may promote students to think actively in class teaching, thus achieve the purpose of innovation ability cultivation.

\section{Pay Attention to Multi-way Teaching Practice, and Comprehensively Improve Students' Operational Ability}

In combination with "Three-basic" test results, we further expand the teaching channel of students' involvement in practice and comprehensively improve their operational ability, with the recitals set as below:

\section{1) Practical teaching in class.}

The segment of practical teaching in class will be conducted in such different teaching sites as on campus or outside school respectively. The practical teaching of professional basic course and part of the professional courses is mainly conducted on campus in the practical training site, with particular emphasis on professional skills training. In recent two years, our college has increased investment in the construction of practical training site and facilities on campus, and has strengthened the hardware foundation of professional teaching, which is a material guarantee for further practical teaching reform, and conducive to introduce design project into class teaching, thus excellent teaching effects is obtained.

\section{2) Practical teaching outside class.}

In the segment of practical teaching outside class, encourage students to participate various professional contests with the requirement that they shall participate at least one design contest during school hours; conduct systematic management for professional practice and summer vacation social practice; carry out quality expansion certificate authentication, and record the participation and awards of design works in to students archives; perfect the evaluation standard, and increase rewards for students who have won awards in design and have published papers. Take initiative to participate in various design practices in practice base; guide students to participate in extensive design contests and exhibition activities; encourage senior class students to work as a part-time designer in companies and enterprises etc.

\section{E. Pay Attention to the Feature of Market-Oriented Teaching, and Inspect the Professional Teaching Quality Using the Market.}

The "Three-basic" test for undergraduates is to test whether or not our talents cultivation quality conforms to social demands. Based on this, we have strengthed our cooperation with industrial association and relevant design companies, providing more practice opportunities for students, enabling them to apply basic knowledge, basic techniques and basic skills to practice. In recent years, we have strengthened the university-enterprise cooperation, and have established good cooperative relationship with Henan Interior Decoration Industry Association, Henan Photographers Association, Henan Comics Industry Association, Henan Province Garment Association and its affiliates.

In order to make the students exercise their basic skills, consolidate basic knowledge, and to promote implementation of practice, our school has cooperated with Daimashi (Zhengzhou) Garment Co., Ltd. in summer vacation of 2011, and arranged nearly 60 students of 2008 specialized in art design (costume design), costume design and engineering to have a 3-month internship in the enterprise. Our students have practiced at a dozen posts in factories, companies and design offices by post practice, with their graphic technique, technological level, pressing technology, standard making technology, sales ability and design capability recognized by the companies, and their ability has been further improved through exercise.

In recent three years, the graduation practice of the graduates specialized in art design (environment art) of our college are all arrange by Henan Decoration Industry Association and its affiliates with good effects. Those companies have become the bridge and link between colleges and society, the important window for students to contact with the society, and to learn about changes of society demand for talents in a timely manner, thus promoting sound development of the professional construction in our school. What is more important is that we can take this opportunity to explore the law of school running of school-enterprise combination in-depth, opening up a new way for professional development and expansion.

The students cultivated by our school will eventually enter the society with their academic outcomes to be tested by the market. The "Three-basic" test is just a teaching evaluation method, and to make the business training requirements in line with the market demand and to integrate into society quickly, we should further strengthen practical teaching for art design major, with the emphasis on cultivation of students' practical ability, innovative spirit and comprehensive quality.

It one of the important ways to conduct the "Three-basic" tests by testing the professional teaching effects and evaluating the talents cultivation quality via market, which will give an intuitive reveal of whether or not our teaching methods, teaching contents and cultivation objective are in line with current social development demands. 
As education quality is one of the important aspects of educational output, the evaluation of it has always been one of the project that people pay attention to and research with focus. The talents cultivation quality shall not only be tested and evaluated in the educational field, but also be tested and evaluated by society, the third party outside the educational field. The "Three-basic" test against students majored in art design forms an important part of teaching quality by third party, and is a positive exploration and beneficial attempt in terms of monitoring and evaluation of the teaching quality, and it is also an innovation based on basic teaching law and education evaluation principles. Innovation and reform not only require the reformer's courage and insight, but also need scientific method and careful organization.

\section{CONCLUSION}

Based on the above mentioned, we need to go beyond the traditional simple course evaluation and break through the dilemma of modeled evaluation behavior, conceptualized and abstracted evaluation index caused by simplified evaluation form. We may take the social staffing standard, national occupational qualification standard and industrial talents quality standard as a basis to make the evaluation standard and evaluation subject diversified, and the evaluation results more objective, making the function of education evaluation to play better. Further make clear of the professional school-running orientation, and find out a talent cultivation quality standard that is in line with the characteristics of schooling and the reality to continuously reform and prefect the cultivation mode of talents specialized in art design.

\section{REFERENCES}

[1] Xisheng Yang, Liao Jianjun and Ye Yongjun. "Exploration and practice of the talent training mode of school enterprise cooperation in the design of art majors" Hunan Journal of social science, J. PP163-165, May 2009

[2] Yanbin Gu, "Exploration and practice of innovative art design talents training mode" Decoration. J. PP72-74, Nov. 2005.

[3] Xiaping Shu, Beibei Zhang "independent college of art and design innovation and application oriented personnel training mode research", "national art research" J. P165, Dce. 2011. 